\title{
CHILD RIGHTS IN SUB-SAHARAN AFRICA: A CALL FOR A RIGHTS-BASED GLOBAL RESEARCH AGENDA
}

\section{Mulugeta Dinbabo}

\section{INTRODUCTION}

Despite many achievements regarding child rights over the last 20 years, including improvements in many indicators such as the significant reduction in infant and child mortality; the more positive way of thinking about and listening to children; and increased response to those who abuse children, the rights of children are still insufficiently protected. Millions of children across the world suffer from the effects of extreme forms of poverty and their associated evils, such as malnourishment, stunted growth, nutritional-deficiency diseases and illiteracy. Recent figures from the International Labour Organisation (2010) show that, globally one in every six children work, 126 million children work in hazardous conditions, and the highest proportion of child labourers is in sub-Saharan Africa, where $26 \%$ of children (49 million) are involved in work. These figures provide only a glimpse of the challenges and obstacles that a child faces around the world.

The case is not that much different in Africa. Information on the situation of African children and, more importantly, knowledge on how to address the enormous, complex situation and sometimes contentious problems facing children is often anecdotal, inadequate and scattered (African Child Policy Forum, 2010). At the same time, with an increase in concern for and interest in children, research and analysis efforts related to children and children's rights by different bodies, such as academia, think-tanks, nongovernmental organisations (NGOs), research networks, international agencies, and multilateral and bilateral donors have also increased. Different approaches and frameworks have also been used by these researchers and organisations who are working towards a better world for children. A child rights-based approach (CRBA) has become an important and unifying concept for stakeholders from a range of disciplines interested in child wellbeing and child protection. Moreover, international organisations such as the United Nations Children's Fund (UNICEF), Save the Children and the United Nations High Commission for Refugees (UNHCR) are advocating a rights-based approach (RBA) in their effort to establish and strengthen a comprehensive childprotection agenda. As guided by the UNCRC (United Nations Convention on the Rights of the Child, 1989), the RBA promotes a holistic view of children and child protection that necessarily engages the full range of actors involved in protecting children's rights. Developing a rights-based global approach agenda that is well-informed by the child research agenda can have a real impact on the lives of children throughout the world. It may change the ways in which the organisations concerned think and act when dealing with children's rights situations. Notwithstanding its importance, formulating a wellinformed child research agenda has been neglected and is currently underdeveloped.

The rationale for a child right-based approach is the need to ensure doing the right thing, morally or legally. It involves integrating child rights, norms, standards and principles in 
policy, planning, implementation and evaluation to help ensure that the programme or the practice respects child rights, in all cases, and supports their further realisation, where possible. The importance and relevance of child rights are clearly articulated within the UNCRC (1989), which is the definitive international treaty regarding child rights. The development of a rights-based global research agenda that responds to the present child-rights situation will seek to hold governments and other duty-bearers accountable and to encourage rights holders to claim their rights. The UN Convention on the Rights of the Child also acknowledges that continuous research is needed to learn and understand how to improve child rights. There is thus a need for a high-quality, long-term national agenda for the collection, analysis and dissemination of information on child rights. Furthermore, the efficient development of the definitions of child rights and the phasing in of research activities are important to ensure that research results feed into the on-going implementation of the roll-out of child rights. The research agenda produced by this study reflects child rights issues of the greatest importance to the research community. The results are of potential benefit to researchers, funding organisations and ultimately to the children in sub-Saharan Africa. In the following sections this paper presents (a) the methodological approach used; (b) the conceptual framework of a CRBA and literature review; (c) an analysis of the experience of researchers and the development of a rights-based global agenda; and (d) conclusions and specific recommendations.

\section{RESEARCH METHODOLOGY}

The research methodology employed a mix of secondary data analysis and field data collection to understand the issues involved in a rights-based global research agenda that responds to the present child rights situation. A purposefully selected group of 85 researchers from more than 20 organisations in sub-Saharan Africa ${ }^{1}$ were interviewed using a semi-structured questionnaire. These included researchers and research institutions involved in research on children, civil associations' representatives, and associations undertaking research on children in a sub-Saharan African region. Meetings at different levels were also conducted. These meetings enabled the researcher to understand the different views, ideas, experiences and perspectives of the participants regarding the promotion of child rights-oriented research in sub-Saharan Africa. In order to arrive at conclusions, the degree of correlation between the information gathered and the theoretical/conceptual framework was used as a guiding principle and parameter.

\section{CONCEPTUAL AND ANALYTICAL FRAMEWORK}

An increasing emphasis has recently been placed on rights-based approaches to address the problems of child protection. In part, this shift has been the result of growing recognition that needs-based or service-delivery approaches have failed to substantially reduce the problem (Dinbabo, 2011; Woll, 2000). To understand and promote an RBA to child protection, one has to start with the definition of a rights-based approach. There

1 Cameroon, Ethiopia, Ghana, Kenya, Malawi, Mozambique, Namibia, Nigeria, Senegal, South Africa, Uganda, Zambia and Zimbabwe. 
is no one source that defines RBA, nor is there a uniform approach. In addition, the way that RBAs are implemented appears to have more to do with the context and objectives of an agency or organisation than the definition of the approach.

An RBA is a conceptual framework for the process of social development that is normatively based on international human rights standards and operationally directed to promoting and protecting human rights (Piron, 2004). A programme or an agency that uses RBA as a framework is working towards the realisation of human rights, as articulated in international human rights law, informed by a range of human rights principles, and fostering human rights capacity in all relevant actors (UNAIDS, 2004). It seeks to analyse inequalities which lie at the heart of development problems and to redress discriminatory practices and unjust distributions of power that impede development progress (Nyamu-Musembi \& Cornwall, 2004). It also seeks to create greater awareness among governments and other relevant institutions of their obligations to fulfil, respect and protect human rights and to support and empower individuals and communities to claim their rights (United Nations Children's Fund, 2011). In an RBA the plans, policies and processes of development are attached in a system of rights and corresponding obligations established by international law. This helps to promote equality and social transformation and the sustainability of development work, empowering people themselves, especially the most marginalised, to participate in policy formulation, and also holds accountable those who have a duty to act (Jonsson, 2003; Nyamu-Musembi \& Cornwall, 2004).

This approach ensures the involvement and participation of all stakeholders, transparency and accountability, monitoring, sustained social development, and the realisation of the rights of the previously excluded. It seeks to analyse inequalities which lie at the heart of social development problems and injustices that hinder development progress (Nyamu-Musembi \& Cornwall, 2004). The rationale for a rights-based approach is usually a blend of two major points. First, the intrinsic rationale is acknowledging that adopting an RBA is the right thing to do, morally or legally. Second, the instrumental rationale recognises that an RBA approach leads to better and more sustainable social development outcomes (Jonsson, 2003). RBA involves integrating rights, norms, standards and principles in policy, planning, implementation and evaluation to help ensure that the programme or the practice respects rights, in all cases, and supports their further realisation, where possible. According to UNICEF (2011:14), the RBA is informed by seven basic principles. 


\section{TABLE 1 \\ THE SEVEN PRINCIPLES OF A RIGHTS-BASED APPROACH}

1. Universality and inalienability: Human rights are universal and inalienable, the entitlement of all people everywhere in the world. An individual cannot voluntarily give them up. Nor can others take them away. As stated in article 1 of the Universal Declaration of Human Rights, "All human beings are born free and equal in dignity and rights."

2. Indivisibility: Human rights are indivisible. Whether civil, cultural, economic, political or social, they are all inherent to the dignity of every person. Consequently, they all have equal status as rights and cannot be ranked in a hierarchy.

3. Interdependence and interrelatedness: The realization of one right often depends, wholly or in part, on the realization of others. For example, realization of the right to health may depend on realization of the right to information.

4. Equality and non-discrimination: All individuals are equal as human beings, and by virtue of the inherent dignity of each person, are entitled to their rights without discrimination of any kind. A Rights Based Approach requires a particular focus on addressing discrimination and inequality. Safeguards need to be included in development instruments to protect the rights and well-being of marginalized groups.

5. Participation and inclusion: Every person and all peoples are entitled to active, free and meaningful participation in, contribution to and enjoyment of civil, economic, social, cultural and political development, through which human rights and fundamental freedoms can be enjoyed.

6. Empowerment: Empowerment is the process by which people's capabilities to demand and use their human rights grow. They are empowered to claim their rights rather than simply wait for policies, legislation or the provision of services.

7. Accountability and respect for the rule of law: A Rights Based Approach seeks to raise levels of accountability in the development process by identifying "rights holders" and corresponding "duty bearers" and to enhance the capacities of those duty bearers to meet their obligations

As Boesen and Martin (2007:11) have pointed out, one of the most fundamental dynamics of a rights-based approach is that every human being is a rights-holder and that every human right has a corresponding duty-bearer. A rights-holder "is entitled to rights; is entitled to claim rights; is entitled to hold the duty-bearer accountable; has a responsibility to respect the rights of others". Consequently, those who have the obligation to respect, protect, and fulfil the rights of the rights-holder are duty-bearers. In the context of applying the RBA to children, children are rights-holders and entitled to their rights, to claim their rights, to hold the duty-bearer accountable, but they also have a responsibility to respect the rights of others. Since we are exploring the application of a right-based approach to a child research agenda, it is of paramount importance to review existing literature on child rights conventions and charters from both global and sub-Saharan perspectives.

\section{LITERATURE REVIEW}

Children's rights have infiltrated social and political discourse as well as policy documentation in recent decades, particularly since the worldwide ratification of the United Nations Convention on the Rights of the child (UNCRC) in 1989. Globally, there is a great deal of literature on the UN Convention on the Rights of the Child (Besson, 
2005; Tang, 2003; Woll, 2000); child rights and protection (Federle, 2000; Sund, 2006), and child rights and participation (Kjorholt, 2002; Thomas, 2007).

Analysis of African literature also indicates that a number of researchers classified the rights of the child in several themes. These include Africare (2004), Ashiabi (2007), Barnes, Noble, Wright and Dawes (2009), Camfield (2010), Chiwaula (2010), Dawes, Bray and Van der Merwe (2007), Dinbabo (2011), Gordon, Nandy, Pantazis, Pemberton and Townsend (2003), Grodem (2008), Bøås and Hatløy (2008), Lund, Noble, Barnes and Wright (2008), Meintjes and Hall (2009), Noble, Wright, Magasela and Ratcliffe (2007), Tekola, Griffin and Camfield (2009), Twine, Collinson, Polzer and Khan (2007) and Wilkinson (2011). The following section provides a summary of the selected thematic literature review (i.e. child labour and child poverty) in sub-Saharan Africa. It identifies gaps in the current situation of children's rights-based research by pinpointing its strengths and weaknesses.

\section{Child rights and child labour}

Researchers, such as Admassie (2002), Akarro and Mtweve (2011), Bøås and Hatløy (2008), Canagarajah and Coulombe (1998) and Chiwaula (2010) assessed the relationship between child rights and child labour. For example Admassie (2002) examined the link between children's labour force participation and some macroeconomic variables, using aggregated data from sub-Saharan Africa. He found that the high incidence of child labour in sub-Saharan Africa could be explained in terms of, among other things, the high incidence of poverty, the predominance of a poorly developed agriculture sector, high population growth and low education attendance. The study stresses that poverty is the most important reason for the high incidence of child labour in Africa. Bøås and Hatløy (2008), using data from four different surveys - street children in Accra, Ghana; street children in Bamako, Mali; children and youths in alluvial diamond production in the Kono district, Sierra Leone; and war-affected children in the Voinjama district, Liberia - tried to analyse how children and youths seek to use different economic strategies to shape their lives. The authors found that in each of these cases child labour is a consequence of poverty, steep school fees and the family need for the income that the children can earn. Akarro and Mtweve (2011) examined the state of child labour and the factors behind it in one of the areas in which child labour is the most prevalent in Tanzania, known as the Njombe district. Using a survey of 300 household heads that were randomly selected from four accessible villages and a Chisquare statistical analysis, the author argued that household poverty was the factor which forced children to engage in economic activities. Hence he suggested that child labour is a reflection of poverty and therefore tackling poverty would have a positive impact on reducing child labour.

Chiwaula (2010) conducted a study to assess the relationship between child-work decisions and household income and asset poverty, using the rural sub-sample of the 2004 Malawi Integrated Household Survey. Using instrumental variable probit models and controlling for child, household and community characteristics, the author reaffirmed the presence of a positive relationship between child labour and income 
poverty, thereby accepting the hypothesis that child work in developing countries is largely a consequence of poverty. Drawing upon feedback from interviews cond ucted in the Talensi Nabdam District, the upper east region of Ghana, Hilson (2010) examined the challenges to eradicating child labour in the artisanal and small-scale mining (ASM) sector and offered policy-relevant options for tackling the problem. The author confirmed that children seem work at ASM because of family hardship, and that child labour in artisanal mining is a product of a wider, multifaceted poverty problem overall.

Canagarajah and Coulombe (1998) examined the determinants of child labour in conjunction with the schooling of Ghanaian children between the ages of 7 to 14 , using national household surveys conducted between 1987 and 1992. They indicated that of the $28 \%$ of children involved in child labour, more than two thirds were also simultaneously in school. Of all the children between 7-14 years, around 90\% were involved in household chores. Moreover, their study revealed that a significant negative relationship exists between going to school and working. Hence increasing mandatory schooling is the effective way of reducing child labour and would ensure that Ghana's human capital is stabilised. Admassie (2003) studied the implications of children's participation in household activities on schooling, using a household survey from rural Ethiopia. The author found that combining work with school attendance is common among school children, although some activities may hamper school attendance more than others. He also proposed that a gradual introduction of a policy on child labour may be necessary in the context of subsistence economies, where initial interventions should aim at making the combination of work and school attendance possible rather than immediately eliminating child labour.

\section{Child rights and child poverty}

Researchers, academics, politicians and analysts in the field argue that there is a need to undertake detailed studies on child rights and child poverty in the sub-Saharan African context (Ashiabi, 2007; Barnes et al., 2009; Barrientos \& DeJong, 2006; Black, Morris \& Bryce, 2003; Camfield, 2010; Dawes et al., 2007; Dinbabo, 2011; Gordon et al., 2003; Grodem, 2008; Levine, Van der Berg \& Yu, 2011; Lund et al. 2009; Lund et al., 2008; Meintjes \& Hall, 2009; Noble et al., 2007; Noble, Wright \& Cluver, 2006; Tekola et al., 2009). The following section provides a brief summary of selected literature in the field.

Dinbabo (2011) sought, in line with Rawls's theory of justice and the conceptual framework of a rights-based approach, to analyse the extent to which social welfare policies, in particular the Child Support Grant, have an impact on poverty and addressing the inequalities of people living in households with children in South Africa. Quantitative methods of research were applied throughout the study and the measurement of poverty was made using an absolute poverty line of R450 per capita per month. Dinbabo (2011) used the South African microsimulation model (SAMOD) to analyse the various scenarios of the social policies. Dinbabo (2011) clearly indicated that there is a positive correlation between cash transfer (Child Support Grant) and a reduction in poverty and the inequalities of people living in households with children in 
South Africa. He also argued that an increase in the Child Support Grant amount and the number of child beneficiaries, in modelling, produced a positive effect in addressing increasing child poverty and vulnerability. Wilkinson (2011) modelled the impact of taxes and transfers on child poverty in South Africa. Her research described how microsimulation modelling can be used to analyse the impact of tax and transfer policy on the situation of children in South Africa. The South African microsimulation model (SAMOD) was used to simulate certain policy reforms announced in the 2008 budget, and implemented during 2008, and to explore the impact of these reforms on children and other age groups across the income distribution. She argued that given that the government has made explicit legislative commitments to children and that poverty rates are highest for households containing children, it might be expected that children would be a priority in policy reforms.

In South Africa Dawes et al. (2007), using a rights-based approach, undertook a comprehensive study and developed a conceptual framework and a classic set of ho listic indicators for monitoring the wellbeing of children in South Africa. With the South African constitution as a background, they made it clear that it is not just the state of the children that is important to measure, but also the circumstances within which the children grow and develop. They provided realistic tools for policy makers to assess the effectiveness of child-based policies and interventions. Camfield, (2010) explored children's understanding of poverty, ill-being and well-being in Ethiopia using data collected through group exercises with children aged 5-6 and 11-13 participating in Young Lives, an international study of childhood poverty. She argued for broadening the focus of child poverty reduction to include the psychosocial costs of lacking the culturally specific resources required for full participation in society. Crivello et al. (2009) examined a selection of methods being used by Young Lives to capture aspects of child wellbeing in the context of a range of children's life experiences related to poverty, specific risks, and protective processes. They draw on a review of the literature on child-focused methods and on recent experiences, piloting three core qualitative methods in the four-study countries. The final result of the research is the development of a methodology that is child-centred but also acknowledges that every child is embedded within a network of social and economic relationships. For example, Tekola et al. (2009) discuss the advantages and challenges of using qualitative methods to elicit poor children's perspectives about threats and positive influences on their wellbeing. Using qualitative methods such as semi-structured interviews, draw-and-tell, and diaries, the kinds of data they produced and the methodological and ethical dilemmas and tensions encountered in using them, they concluded that despite the challenges, qualitative methods are invaluable in order to understand what poor children see as threats or positive influences on their wellbeing.

Dieden and Gustafsson (2003) assessed child poverty, based on micro data for 1995. Using multivariate analyses techniques, the study examined a child's dichotomous poverty status (i.e. either poor or non-poor) and was conceived to be associated with various characteristics of the household, which were perceived as affecting the probability of the child being poor. Through the application of logistic regression 
analysis, a parameter was associated with each characteristic included in the analysis. The result indicated that, on average, children living in South Africa face a risk of being poor comparable to the average world inhabitant. A similar study was conducted in South Africa by Twine et al. (2007). Using a descriptive cross-tabulation and multivariate logistic regression, they analysed the interplay between the child support grant and child poverty. The result of their study indicates that although these grants are intended as a pro-poor intervention, the poorest households are less likely to apply for grants than those in higher socioeconomic brackets. The study concludes that enhancing access will require improved provision of birth certificates and identity documents, efficient co-ordination and service provision from a range of rural government offices, and creative methods of communication.

A study by Meintjes and Hall (2009) indicates that poverty remains a serious issue in South Africa, most significantly child poverty. Using a quantitative indicator, Meintjes and Hall established the child poverty rate line as R350 per person per month. In 2007 $68 \%$ of children lived in households with a per capita income of below R350, while in the Eastern Cape and Limpopo eight out of ten children lived in households with a low level of per capita income (Meintjes \& Hall, 2009). However, the financial circumstances of the very poorest of the poor are to some extent improved upon by an increment in the Child Support Grant from R100 as of 1998 to R240 in 2009. Notwithstanding government attempts to address the issue of poverty partially through social assistance provision, the harsh impact of poverty is still felt amongst children as, in some regions, 8 out of 10 children live in households with a low level of per capita income, an indication that most household members are without employment. This warrants an amendment to government administration and management strategies in addressing the issue of poverty, such as introducing a universal basic income grant (BIG) and improving the quality of education.

Camfield (2010) undertook research on child poverty in Ethiopia. This study explored children's understanding of poverty, ill-being and well-being in Ethiopia, using a qualitative study that used local concepts of living well or badly to explore Ethiopian children's understanding of poverty. Five sites were chosen from the five regions selected for the Young Lives longitudinal surveys, which are based on a much larger sample of 3000 children and their caregivers in 20 sites. The results of the study indicate that child poverty in Ethiopia is very severe and suggest that interventions to address childhood poverty should provide resources for social participation as well as survival, and recognise the operation of mechanisms of power, both directly through coercion and indirectly through shaping children's understandings of their lives.

Harper and Marcus (1999) assessed child poverty using a qualitative research approach in sub-Saharan Africa. Their study details a wide range of aspects of child poverty and concludes that investing in the development and protection of Africa's children is not a choice, it is a priority. According to them, targeting child poverty requires an integrated and holistic approach supporting the communities in which children live, addressing their basic needs, and promoting participatory development, which will not only produce active citizens of the future but will also provide sustainable solutions to child poverty. 
Hope's (2005) study also indicates that child poverty in the sub-Saharan Africa region is very severe and complicated as a result of unique social, economic and political problems, cultural and developmental circumstances, as well as the frequent disaster situations, armed conflict, famine and hunger experienced.

Several authors have argued that sub-Saharan Africa child survival is related to the degree of poverty suffered. However, Black et al. (2003) observed that though poverty is the most important cause of the low child survival rates in sub-Saharan Africa, a number of other factors, also related to poverty, give rise to child mortality. These include unsafe living conditions, unclean drinking water, absence of sanitation and associated health problems, lack of knowledge on birth control, and poor knowledge of the importance of breastfeeding practices. Research conducted by UNICEF (2005) and Hope (2005) identified that, compared to other regions, sub-Saharan Africa is the region where the greatest proportion of children are always at risk, for many reasons. Some of the reasons include dire poverty, communicable disease, inappropriate feeding habits and malnutrition, loss of parents, high infant mortality, and sexual and labour abuse, which have been increasing at an alarming rate over the past few decades. An Africare (2004) study noted that in sub-Saharan Africa every single day a number of children die without having proper medication. Most child deaths are health-related. According to UNICEF (2004) estimates in 2004, more than 12.3 million children below the age of 18 had lost both parents, in one way or another. UNAIDS (2003) also warned that unless serious measures are taken the worst-case scenario is that by the year 2025 about 27 million children in Africa might be orphaned by AIDS. Gordon et al. (2003) also did research in the African region as part of a global-level study on severe deprivation. Their results indicated that children in rural areas are much more deprived than those in urban areas. Children born in country settings encounter almost twice as much risk than those born in towns. Furthermore, a difference between Africa's regions was noted; in comparison to other regions, the degree of risk for children in North Africa is relatively low. In general, studies such as Gordon et al. (2003) and UNICEF (2007) have shown that the maximum rate of one-dollar-per-day poverty in Africa is mostly found in the western and central parts of Africa.

In South Africa Lund et al. (2009) undertook a study of conditional cash transfers and of issues relating to the implementation of the unconditional Child Support Grant. Their research examined the implication of conditional cash transfers in depth. According to their findings, the biggest challenges with regard to gaining access to different services, such as health services and education, are mainly supply-side issues instead of questions of personal motivation. Levine et al. (2011) undertook an analysis of the impact of cash transfers on household welfare in Namibia. Multivariate analysis presented in this research confirms that these transfers play an important role in alleviating poverty, especially for the very poor. They noted that the poverty-reducing effects of the child grants are likely to increase further as access is being rapidly expanded. They argued that the impact in terms of reducing Namibia's extremely high inequality is limited. The quantitative research of Barrientos and DeJong (2006) indicates a positive correlation of 
the number of children in a household and the depth of poverty. They argued that cash transfers targeted towards children have strong effects in alleviating poverty.

Many analysts (Barnes et al., 2009; Gordon et al., 2003; Grodem, 2008; Lund et al., 2008; Noble et al., 2007; Noble, Wright and Cluver, 2006) have suggested a combination of monetary and deprivation approaches to assess child poverty. As the shortcomings of traditional definitions of and approaches to child poverty measurements have become more apparent, Noble et al. (2007), in the historical context of South Africa, proposed a multidimensional model of child poverty. The conceptualisation of poverty in the model is broadly defined to include many different forms of deprivation. The model contains eight examples of dimensions of deprivation, including health, material, human capital, social capital, living environment, adequate care, physical safety and a result of abuse. The concept of poverty, which the measurement of the model is built around, blends the concepts of relative and absolute poverty. At the core of the model is a multidimensional conceptualisation of absolute child poverty. This is complemented by a relative, multidimensional concept of poverty and social exclusion (Noble et al., 2007).

Using data from the Ghana Living Standards Survey, 1991/92 and 1998/99, and the Ghana Demographic and Health Survey, 1993 and 1998, Ashiabi (2007) undertook a study to ascertain the relationship between poverty and children's nutritional health status and schooling in Ghana. The study indicates that poverty impacts on parental ability to provide adequate nutrition and health care, and suggests that child malnutrition has effects into adulthood, as evidenced by the reduced work capacity and intellectual performance of adults who grew up malnourished.

\section{Summary of strengths and weakness}

From the above analysis of the selected literature review, the following section provides an overview of strengths and weaknesses of children's rights-based research in subSaharan Africa.

Strengths: there is a growing appreciation among academics, researchers and civil society of a legal, normative framework. The child rights-based approach helps to bring more objectivity to child labour and child poverty work, and allows for more rational argumentation in favour of development. Academics, researchers and civil society organisations have achieved some success in terms of child rights-based research and changing policy to be more inclusive and responsive to children's priorities. Second, the existence of global and continental-level legal instruments, such as the Convention on the Rights of the Child (CRC) and the African Charter on the Rights and Welfare of the Child (ACRWC), provided the overarching legal framework with reference to child rights-based research in sub-Saharan Africa. Third, efforts have been made towards the promoting the participation and inclusion of children and communities in programmes targeting child rights. Some of these researchers touched slightly on issues related to the rights-based approach to child labour and child poverty. Yet research such as the Dinbabo (2011) study indicates that there is inadequate understanding of the constitutional rights of the child. Fourth, the literature by researchers in sub-Saharan 
Africa indicates that the normative framework that can be established by adopting a child rights-based approach can be implemented in all areas of social and economic development of the child. Child rights are not applied temporarily, but rather established as a new frame of reference, which will be gradually anchored in the basic rights of the child. Fifth, a few African rights-based researchers are playing useful roles in bringing government officials and other stakeholders together to explore what services need to be in place to assure children's rights.

Weaknesses: literature in the field has been focused on specific regions and this may result in research that is skewed towards certain topics and prevents researchers from exploring new areas that may be important and instrumental in achieving a better status for children in sub-Saharan Africa. Second, there is limited integration of research on children's rights as an integral part of mainstream social science research and constraint of research in the area of networking of African researchers. In addition, there is very limited literature which identifies the relationship between rights-based research, poverty, health education, youth justice, and drug/alcohol use among youths in Africa. Third, most of the reviewed literature in sub-Saharan Africa offers very limited theoretical frameworks for locating rights-based approaches in relation to children. In addition, the vagueness in the formulation of the child rights approach in several publications leaves gaps (particularly in the field of child poverty, child labour, and economic and social rights), so that deriving certain 'rights' from these remains a matter of interpretation. Fourth, despite a limited amount of sub-Saharan African literature which discusses a child rights-based approach, most of the literature reviewed is often vague in its formulation and leaves room for interpretation and inadequate implementation. The child rights-based approach does not offer an operational blueprint or conceptual framework for a child right-based approach.

All these points imply that researchers in the field have little impact on policies and laws and, consequently, the children, families and communities often lose faith in both policy and research. The central focus is narrow, excluding the underlying causes of violations of child rights, which is pivotal in child rights-based research. The need to undertake research, explore best practices of implementation modalities and dissemination of results on child rights-based approach in sub-Saharan Africa is evident. Against the background of the literature review on child poverty and child labour abuse, the following section presents an analysis of experiences and offers a scientifically sound rights-based global research agenda. This will help to better inform the policy debate on how the child rights-based approach can be improved in sub-Saharan Africa.

\section{ANALYSIS OF EXPERIENCE}

Analysing researchers' experiences is considered an important component in social science (McIntyre, Byrd \& Foxx, 1996). Most social science research projects have incorporated more and more experience analysis into their research programmes (Garibaldi, 1992). The primary purpose of experience analysis in this research is to understand how researchers deal with the rights-based research and apply theory and principles to the realities of research situations. In order to understand the research 
experience, various organisations and child researchers from sub-Saharan African countries were asked about their personal work experience and their familiarity with rights-based research in the field. The following themes emerged from the analysis of these comments.

\section{Respondents' experience of rights-based research}

According to the information received, $88.6 \%$ of the respondents had previously embarked on various types of child research and designed a child rights-based approach (CRBA) to various types of research project/programmes. Some of the most important inputs to the data on informants' experiences included written descriptions and reflections on rights-based approaches in action, broadening understanding of the implications of child rights-based research (CRBR) integration in their research activities, and fostering of learning across different parts of the CRBR initiatives and case studies. Respondents indicated a diverse range of contexts and approaches, and thus added their perspectives to the creative array of options available for CRBR application. Taken together, they revealed the real differences in explicit focus on RBA application and its partners at all stages of the programme process, providing important insights into the theoretical and practical implications of an RBA. More importantly, however, they also raised a number of key issues and questions for further consideration.

The information gathered indicates that $73 \%$ of respondents had either worked directly or indirectly towards developing a rights-based agenda. It was constantly noted of child rights-based research that the majority of the respondents had previously employed it in order to advocate for socio-economic and political rights of children and the powerless in society through their organisations. Respondents indicated that CRBR is shedding a new light on the role that social injustice, discrimination and lack of representation plays in the lives of many children caught in an endless cycle of poverty. About 54\% respondents also indicated that looking at child research through a 'rights' lens helped them in designing a new way of devising a research framework and in orienting themselves progressively towards addressing rights through advocacy and the strengthening of civil society. All of the respondents agreed that CRBR requires analysis that pushes children to reflect beyond the commonly stated problems and to enter into the uncomfortable, the hard-to-discuss, but critically important, factors about power relations that have to be tackled for the issues to be meaningfully addressed. Respondents also raised their concern about the general lack of a sound theoretical framework and strong empirical basis for RBA. They also pointed out their concern about the researchers' expertise in RBA methodology and scarcity of research findings and evaluation strategies. In summary, each of the respondents' cases demonstrates that CRBR will need to develop its in-house capacity to assess, interpret and synthesise information about the rights issues that underpin economic, social, political and cultural matters and to design programmes that seek to address them.

\section{Strengths and weaknesses}

In an attempt to understand the strengths and weaknesses of child rights-based research in sub-Saharan Africa, different types of questions were raised. In this regard, a range of 
views were expressed by respondents. A summary of participants' views is presented below.

Strengths: altogether $74.4 \%$ of the respondents stated that CRBR helped in deepening the focus on disadvantaged and socially marginalised children as well as fostering respect and dignity and enhancing the opportunities of neglected children. Respondents also indicated that the presence of the CRC framework was an important strength in terms of undertaking CRBR in sub-Saharan Africa. In an interview one of the child rights researcher's indicated that:

"...in Africa the CRC is not alone in the quest for expanded boundaries of children's rights. It is supplemented by the African Charter on the Rights and Welfare of the Child (ACRWC or the Charter). It was in order to give the CRC specific application within the African context that the Charter - the first regional treaty on the human rights of the child - was adopted by the then $O A U$ (now African Union or AU) Heads of State and Governments on 11 July 1990. It has also indicated that the Charter, while upholding all the universal standards outlined in the CRC, speaks to the specific problems that African children confront, for example, the impact of armed conflicts, harmful traditional practices, apartheid that prevailed at the time, and so forth." (Ghanaian South African respondent)

For instance, $67 \%$ of the respondents also indicated that within African culture and value system the Charter provides for the responsibilities of children to their parents, to their communities and to society as a whole, relative to their age and ability. Respondents also argue that child rights-based research is crucial in transforming the relationships between governmental and development agencies and the recipients, and it can help bridge theoretical gaps between political, civil, social and economic rights of children by assisting others in understanding how they are interconnected in practice. In general, $73.8 \%$ of respondents confirmed that CRBR raises awareness of the gaps in this area and further provides new approaches and interventions in the sector, thus paving the way for future research on similar themes.

Weaknesses: up to $87 \%$ of the respondents indicated that the main weakness is very poor child rights networking. Respondents also pointed out that research networking is about using different mechanisms to discover and use research and scholarly information about child rights-based research. Respondents in the field indicated that research networking serves as a knowledge management system for research institutions and African childrights researchers. For example, one of the respondents indicated that

“... research networking can connects systems, at the continental, national, local and individual research networks, publicly available research data (e.g. grants and publications), and restricted/proprietary data by harvesting information from disparate sources and compiling expertise profiles for investigators, scholars, civil society members, community partners, and facilities." (South African respondent) 
More than $85 \%$ of the respondents in the field believe that research networking facilitates rapid development of new collaborations and teams of researchers to address new or existing research challenges through the linking of recommendations of researchers, their expertise and sufficient resources. However, in general within the subSaharan region there is very limited and very weak research networking among researchers in Africa. Furthermore, respondents cited the lack of strategic focus and comprehensiveness of child rights-based research as a major weakness. Issues of children's rights cover a number of stakeholders, across various geographical and political boundaries, who should participate in the process; however, to date this has not been taken into account. Moreover, about $47.5 \%$ also claimed that researchers employ inappropriate research methods for child research. According to them, it has become common for researchers to employ inappropriate design and methods, especially when using children as the research subjects. Respondents also suggested that the results of research relevant to children's rights issues should be dis seminated; that children's rights research in Africa should be supported and ensured by adequate financial and material resources; and that the possibility of developing a network of African researchers should be explored.

Child rights-based research organisations and individuals are involved at the global level, with efforts ranging from research to awareness-raising to advocating for the rights of the child and for funding to keep up the momentum for current initiatives. SubSaharan Africa is part of various global networks and strives to achieve synergy with all those that are a part of the agenda to undertake the CBRA (Dinbabo, 2011; NyamuMusembi \& Cornwall, 2004). All these factors indicate a need for expanding and improving the existing networking and advocacy. This can be done through initiating and maintaining contact with individuals and organisations that share or support common goals and agree to work together to achieve those goals. Through advocacy, networks can engage in high-level dialogue with child-research organisations, researchers, policymakers and other influential leaders on broad policy issues and national policies. Policy issues at the operational level are another potential focus for a campaign. Such issues might deal with the formulation of specific resource allocation and service delivery guidelines. Advocacy includes single-issue, time-limited campaigns and on-going work undertaken by a network around a range of issues - conducted at the continental, regional, national or local level.

\section{Opportunities and challenges}

Undertaking child rights-based research allows the researcher to understand issues of child interest and welfare from a first-hand perspective. With the objective of understanding the opportunities and challenges in undertaking CRBR in sub-Saharan Africa, the respondents were asked about the various prospects for the field throughout the entire sub-Saharan African region.

Opportunities: more than $72 \%$ of respondents indicated that the popularity of the CRC and the Charter presents a good opportunity to undertake CRBR. Respondents claimed that a high level of normative consensus exists among the various nations of the world 
(particularly in sub-Saharan Africa) on the idea and content of children's rights as human rights. Respondents also note that, in fact, a significant number of African countries have either completed or are in the process of completing major children's law reforms. This therefore shows commitment to the furtherance of children's rights on the continent. For example, South African respondents pointed out that the promulgation of the new Children's Act presents a new arena and offers ideal opportunities to undertake CRBR. However, respondents also indicated that it should be noted that the degree to which these instruments and laws will improve children's lives depends greatly on how state parties implement them and adopt domestic measures to comply with their obligations under the Act. Respondents listed adverse factors that interfere with the implementation and enforcement of children's rights, especially in Africa. Respondents clearly explained that CRBR enables researchers and research institutions to develop a specific contextual framework for exploring issues of child welfare in the sub-Saharan region. They also believe that undertaking CRBR in sub-Saharan Africa will provide the opportunity for the development of methodologies and strategies that are culturally grounded. Respondents also commented that, even though weak, the availability of the country-level legal framework can be considered as a good opportunity for the development and expansion of CRBR.

Challenges: analyses of the feedback of respondents indicated that there is some resistance among development organisations to CRBR because it is perceived as too political. Similarly, human rights groups sometimes resist engaging in matters relating to the economic, social and cultural rights of the child. Several respondents noted that fears are related to the prospect of losing funders, their public image, legal requirements and other risks in a few sub-Saharan African countries. In addition, some challenges had to do with different vocabulary, language and expectations. For example, one of the respondents noted that "different groups and individuals mean different things when they say 'rights-based approach' or 'participation'. This is also a problem within child rights-based research organisations in sub-Saharan Africa". Among respondents, resistance to new approaches is due to a narrow or limited understanding of rights as solely having to do with a supposedly neutral human rights system, and fear of the political implications of trying to broaden it. Respondents also explained the prevalent gap between theory and practice when it comes to participation and empowerment. They indicated that some of them feel well versed in CRBR theory but are less certain about how to operationalise it. In this regard, one of the challenges presented by respondents is their concern that rights-based approaches may lack conceptual validity, operational effectiveness and widespread relevance within international development. Respondents argue that although children, like adults, are subjects of rights and equally entitled to have those rights respected, children are not adults. They have a different legal status; they are entitled to additional protections deriving from recognition of their vulnerability and youth; and they have differing levels of capacity for exercising rights, depending on their context, experience, cultural environment and age. This finding also supports the studies done by Ochaita and Espinosa (1997) and Tang (2003). 
The above evidence suggests that there are opportunities and challenges in conducting CRBR. However, the respondents stated that research should be aimed at strengthening the resilience of vulnerable children, which is particularly relevant if participatory approaches and tools are used. In general, the overriding theme that emerges from this analysis is that child-research organisations and researchers in sub-Saharan African countries face very similar challenges in making progress. Each of them has ideas, research, tools, resources and models from which others could learn and benefit. There is evidence of significant duplication of learning as well as of considerable opportunities for fruitful dialogue and information exchange.

\section{Proposal for a rights-based global research agenda}

In an attempt to understand the propositions for the development of a rights -based global research agenda that responds to the present child rights situation in sub-Saharan Africa, different types of questions were raised. Respondents suggested that despite the numerous conventions to which most governments in sub-Saharan African may have been signatories, the promotion of child rights issues for many countries still remains under-explored. In this regard, respondents in the field indicated that a global research agenda on child rights should address the following issues:

- Protection and promotion of child rights from the level of the family to that of the state, with the key emphasis being placed on institutional and socio-cultural hindrances that reduce or limit the incentive for child rights promotion and research in general in this area;

- The areas of child protection and children as victims of family violence, including: data collection on victims, particularly over time; family violence prevention and intervention measures; and evaluation of the therapy available;

- Mental health needs, and particularly the efficacy of mental health primary prevention programmes; health promotion and health education programmes; disparities in health outcomes and access to health services; and the reproductive health of young people;

- The youth justice area, the link between youth offences and drug/alcohol use; the link between having been a victim of family violence and youth offending; and what works to reduce youth offending;

- A lack of research on female youth offending. Has there been an increase in female youths charged by the police? Has there been an increase in female youths processed through the youth court system at national and regional level? Are female youths getting more violent?

- The need for further research in specialised sectors to assess where opportunities and gaps exist for ensuring that the rights of children are included. Suggested issues include: health services, approaches to disability, and country strategies affecting food security; 
- Linkages between the children's rights sector and others outside that sector can be fostered in order to mainstream children's rights perspectives in law and policy initiatives outside of dedicated child law reform efforts;

- Research in the area of childhood, children and children's rights, particularly at local level;

- Theoretical work that locates rights-based approaches in relation to development theory more broadly; case studies that analyse the processes involved in adopting rights-based approaches within research institutions; evaluative analyses of what has happened once child rights have been secured; comparative analyses of child rightsbased approaches against other development strategies and models;

- Integrated research on children's rights in sub-Saharan Africa as an integral part of mainstream African social science research;

- Undertaking research on the possibility of developing a network of African researchers who might act in an advisory capacity to the monitoring body of the OAU African Charter on the Rights and Welfare of the Child, once that instrument enters into force.

To effectively undertake a rights-based global research agenda, programmes and projects need to be developed that conduct training for and promote awareness among community members, including children, in order to ensure dissemination of information based on a human rights discourse, in collaboration with the state and local as well as international civil society organisations. However, these projects should be participatory in approach and experiences and scenarios of the sub-Saharan African context should be taken as input for any research conducted under the theme of CRBR. Giving recognition to African culture, pride, value, respect, principles and doctrines is crucial in facilitating acceptance of a rights approach.

Respondents also indicated that research should be based on African traditions of selflessness, tolerance and collectivism to provide foundations on which to build. In this regard, respondents suggested that respect and use of cultural paradigms provide the breathing space needed to further knowledge, acceptance and potential application of child rights-based research to advance wellbeing. In general, the conceptual links between health, education, social welfare policies, and human rights and respondents' perceptions about child rights-based research approach were the key points of enquiry emerging from and informing the child-research community in sub-Saharan Africa. All these points imply that there is an urgent need to consider a rights-based global research agenda that responds to the present child-rights situation in sub-Saharan Africa and conduct research on the rights of children to health and education programmes; in the areas of justice, family violence and female youth offenders; on specialised fields such as approaches to disability and country strategies affecting food security; on law and policy initiatives; on rights-based approaches in relation to development theory; on comparative analyses of child rights-based approaches; and on developing a network of African researchers. These research agendas should be participatory in approach and should be able to consider the culture and values of the African child. In general, 
experiences and scenarios of sub-Saharan Africa should be taken as input for any research conducted under the theme of child rights-based research.

\section{SUMMARY OF FINDINGS}

The rights of the child in the global and universal context received serious focus and attention after the declaration by the General Assembly of the United Nations on the Convention on the Rights of the Child (1989). The basic premise of the CRC is that children (all human beings below the age of 18) are born with fundamental freedoms and the inherent rights of all human beings (Dinbabo, 2011; Woll, 2000). A child should enjoy all the human rights laid down or proclaimed in the constitutions of the individual countries and, particularly, in international conventions or declarations. The CRC establishes, in international law, that governments must ensure that all children without discrimination in any form - benefit from special protection and assistance (Convention on the Rights of the Child, 1989). The result of the assessment demonstrates there is a great demand for urgent action on planning a rights -based global research agenda that responds to the present child-rights situation. Suggestions are thus provided to inform and inspire governmental and non-governmental organisations that are dealing with the rights of children in sub-Saharan Africa. In addition, the research process identified four interrelated gaps that hinder the successful implementation of a rights-based research agenda. First is the existence of insufficient networking, communication and synergy between researchers, practitioners, government officials, funding agencies, research organisations, GOs, NGOs and researchers. Second is the absence of funding for major child rights-based research, which represents a significant obstacle to improving child rights-based research. Third is that there is an inadequate understanding among researchers of the theoretical and conceptual framework of rights based research. Fourth is the insufficiency and inaccuracy of data, which presents a major challenge for the investigator wishing to undertake child rights-based research. Within the context of the abovementioned analysis, the study finally brings into focus general observations gained from the investigation and provides 10 key priorities for a global research agenda in sub-Saharan Africa. The following high-priority research categories are suggested for study in this regard.

- Children as survivors of family violence, including: data collection on victims, particularly over time; family violence prevention and intervention measures; and evaluation of the intervention modalities through the formulation of legislation and policies such as the South African Domestic Violence Act, 1998.

- Children's rights, legal issues and policies which promote and further personal development and which extend to the maximum the protection of children, rather than merely narrow, technocratic analyses of legal provisions.

- Diversion and programming for children at risk or in conflict with the law. There is a great need for research into the regulation of issues of children at risk and prevailing conditions that threated them, which, it is suggested, is an area of weakness in the region as a whole. 
- Legal and policy research agendas in the African context should be embedded in an approach which is informed by juvenile justice and restorative justice practices, as well as being focused on especially vulnerable groups (migrant children, street children, children deprived of their liberty, etc.).

- Mental health needs, and particularly the efficacy of mental health primary prevention programmes; health promotion and health education programmes; disparities in health outcomes and access to health services; and the reproductive health of young people.

- In the field of youth justice, the link between offences by youths and drug/alcohol use; the link between having been a victim of family violence and committing offences; and what works to reduce offending by youths.

- Protection and promotion of child rights from the level of the family to that of the state with the key emphasis placed on institutional and socio-cultural hindrances that reduce or limit the incentives for child-rights promotion.

- Research in specialised sectors to assess where opportunities and gaps exist for ensuring that the rights of children are included. These should include health services, approaches to disability, and the strategies of various countries that affect food security.

- Theoretical work that locates rights-based approaches in relation to development theory, and more broadly, case studies that analyse the processes involved in adopting rights-based approaches within research institutions (e.g. evaluative analyses of what has happened once child rights have been secured, and comparative analyses of child rights-based approaches against other development strategies and models).

- Integration of research on children's rights in sub-Saharan Africa as an integral part of mainstream African social science research and research on the possibility of developing a network of African researchers.

\section{CONCLUSION}

Investment in the child rights-based research (CRBR) on a continental level is necessary to overcome the obstacles currently impeding CRBR in sub-Saharan Africa (Dinbabo, 2011). Funding is needed to increase networking and communication and synergy between researchers, practitioners, government officials, funding agencies and research organisations. Increased financial support is also necessary to develop an effective institutional base that drives the design of the CRBR system, including establishing networks, publication of the research outputs, facilitating conferences, seminars, workshops and capacity-building programmes. Innovative strategies, such as sustained advocacy at all levels to make CRBR easier to accomplish, must be formalised and implemented. Researchers must have access to data, research outputs and outcome information so that the impact of CRBR can be evaluated and improved. Incorporating standard scientific methodology into the evaluation of technical advances in CRBR is crucial. Research is the key to maintaining an appropriate focus on improving the overall 
CRBR in a competitive and cost-conscious manner. Most importantly, it is essential to ensure that the best possible child rights-based research is undertaken in the sub-Saharan African setting.

\section{REFERENCES}

ADMASSIE, A. 2002. Explaining the high incidence of child labour in Sub-Saharan Africa. African Development Review, 14(2):251-275.

ADMASSIE, A. 2003. Child labour and schooling in the context of a subsistence rural economy: can they be Compatible? International Journal of Educational Development, 23(2):167-185.

AFRICAN CHARTER ON THE RIGHTS AND WELFARE OF THE CHILD (ACRWC). 1990. Doc. Organisation of African Unity. 1990. CAB/LEG/24.9/49. Addis Ababa.

AFRICAN CHILD POLICY FORUM (ACPF). 2010. International and regional legal instruments on children. Child Law Resources, 1:1-580.

AFRICARE. 2004. The Food Security Program Capacity Index (FSPCI). Unpublished Internal Guidance. Washington DC.

AKARRO, R.R.J. \& MTWEVE, N.A. 2011. Poverty and its association with child labour in Njombe District in Tanzania: the case of Igima Ward. Curr. Res. J. Soc. Sci., 3(3):199-206.

ASHIABI, G.S. 2007. Play in the preschool classroom: its socio-emotional significance and the teacher's role in play. Early Childhood Education Journal, 35(2):199-207.

BARNES, H., NOBLE, M., WRIGHT, G. \& DAWES, A. 2009. A geographical profile of child deprivation in South Africa. Child Indicators Research, 2(2):181-199.

BARRIENTOS, A. \& DEJONG, J. 2006. Reducing child poverty with cash transfers: a sure thing? Development Policy Review, 24(5):537-552.

BESSON, S. 2005. The principle of non-discrimination in the convention on the rights of the child. International Journal of Children's Rights, 13(4):433-461.

BLACK, R.E., MORRIS, S.S. \& BRYCE. J. 2003. Where and why are 10 million children dying every year? Lancet, 361(9376):2226-2234.

BØÅS, M. \& HATLØY, A. 2008. Child labour in West Africa: different work different vulnerabilities. International Migration, 46(3):3-25.

BOESEN, J. \& MARTIN, T. 2007. Applying a rights-based approach, an inspirational guide for civil society. The Danish Institute for Human Rights, Copenhagen.

CAMFIELD, L. 2010. Outcomes of orphanhood in Ethiopia: a mixed methods study. Social Indicators Research, 104(1):87-102.

CANAGARAJAH, S. \& COULOMBE, H. 1998. Child labor and schooling in Ghana. Policy Research Working paper no. 1844. The World Bank: Washington D.C. 
CHIWAULA L. 2010. Household poverty and child labor decisions in Malawi. In: RANDALL, K.Q., AKEE, E.V. \& EDMONDS, K.T. (ed) Child labor and the transition between school and work (Research in Labor Economics, Volume 31), Emerald Group Publishing Limited, 33-51.

CRIVELLO, G., CAMFIELD, L. \& WOODHEAD, M. 2009. How can children tell us about their wellbeing? Exploring the potential of participatory research approaches within young lives. Journal of Social Indicators Research, 90(3):51-72.

DAWES, A., BRAY, R. \& VAN DER MERWE, A. 2007. Monitoring child wellbeing: a South African rights-based approach. Cape Town: HSRC Press.

DIEDEN, S. \& GUSTAFSSON, B. 2003. Child poverty in South Africa: an assessment based on microdata for 1995. International Journal of Social Welfare, 12(4):326-338.

DINBABO, M. 2011. Social welfare policies and child poverty in South Africa: a microsimulation model on the Child Support Grant. Bellville: University of the Western Cape. (PhD Thesis)

FEDERLE, K.H. 2000. Children's rights and the need for protection. Family Law Quarterly, 34(3):421-440.

GARIBALDI, A. 1992. Preparing teachers for culturally diverse classrooms. In: DILWORTH, M.E. (ed) Diversity in teacher education: new expectations. San Francisco: Jossey-Bass, 23-39.

GORDON, D., NANDY, S., PANTAZIS, C., PEMBERTON, S. \& TOWNSEND, P. 2003. Child poverty in the developing world. Bristol: Policy Press.

GRODEM, A.S. 2008. Household poverty and deprivation among children: how strong are the links? Childhood, 15(1):107-125.

HARPER, C. \& MARCUS, R. 1999. Child poverty in Sub-Saharan Africa. Africa Poverty Status Report. SC UK, London.

HILSON, G. 2010. Child labour in African artisanal mining communities: experiences from Northern Ghana. Development and Change, 41(3):445-473.

HOPE, K. 2005. Child survival, poverty, and labor in Africa. Journal of Children \& Poverty, 11(1):19-42.

INTERNATIONAL LABOUR ORGANISATION (ILO). 2010. World of work report 2010: from one crisis to the next? International Labour Office. Geneva: Switzerland.

JONSSON, U. 2003. Human rights approach to development programming. Nairobi: UNICEF.

KJORHOLT, A.T. 2002. Small is powerful - discourses on 'children and participation' in Norway. Childhood - a Global Journal of Child Research, 9(1):63-82.

LEVINE, S., VAN DER BERG, S. \& YU, D. 2011. The impact of cash transfer on household welfare in Namibia. Development South Africa, 28(1):39-59. 
LUND, F., NOBLE, M., BARNES, H. \& WRIGHT, G. 2008. Is there a rationale for conditional cash transfers for children in South Africa? SDS Working Paper No. 53. Durban: School of Development Studies, University of KwaZulu-Natal.

LUND, F., NOBLE, M., BARNES, H. \& WRIGHT, G. 2009. Is there a rationale for conditional cash transfers for children in South Africa? Transformation, 70:70-91.

McINTYRE, D.J., BYRD, D.M. \& FOXX, S.M. 1996. Field and laboratory experiences. In: SIKULA, J. (ed) Handbook of research on teacher education (2nd ed). New York: Simon Schuster Macmillan, 71-193.

MEINTJES, H. \& HALL, K. 2009. Demography of South Africa's children. In: PENDLEBURY, S., LAKE, L. \& SMITH, C. (eds). South African child gauge 2008/2009. Cape Town: Children's Institute, University of Cape Town, 71-78.

NOBLE, M., WRIGHT, G. \& CLUVER, L. 2006. Developing a child-focused and multidimensional model of Child Poverty for South Africa. Journal of Children and Poverty, 12(1):39-53.

NOBLE, M., WRIGHT, G., MAGASELA, W. \& RATCLIFFE, A. 2007. Developing a democratic definition of poverty in South Africa. Journal of Poverty, 11(4):117-141.

NYAMU-MUSEMBI，C. \& CORNWALL，A. 2004. What is the "rights-based approach" all about? Perspectives from international development agencies. Working Paper No. 234. Brighton: Institute of Development Studies.

OCHAITA, E. \& ESPINOSA, M.A. 1997. Children's participation in family and school life: a psychological and development approach. International Journal of Children's Rights, 5(3):279-297.

PIRON, L.H. 2004. Rights-based approaches to social protection. ODI paper for DFID. London: DFID.

SUND, L.G. 2006. The rights of the child as legally protected interests. International Journal of Children's Rights, 14(4):327-337.

TANG, K.L. 2003. Implementing the United Nations convention on the rights of the child - the Canadian experience. International Social Work, 46(3):277-290.

TEKOLA, B., GRIFFIN, C. \& CAMFIELD, L. 2009. Using qualitative methods with poor children in urban Ethiopia: opportunities \& challenges. Social Indicators Research, 90(1):73-88.

THOMAS, N. 2007. Towards a theory of children's participation. International Journal of Children's Rights, 15(2):199-218.

TWINE, R., COLLINSON, M.A., POLZER, T.J. \& KHAN, K. 2007. Evaluating access to a child-oriented poverty alleviation in South Africa. Scandinavian Journal of Public Health, 35(69):118-127.

UNITED NATIONS CONVENTION ON THE RIGHTS OF THE CHILD (UNCRC). 1989. UN General Assembly Document A/RES/44/25. New York. United Nations. 
UNITED NATIONS CHILDREN'S FUND (UNICEF). 2004. Report on the progress for Children, Vol. I. New York. UNICEF.

UNITED NATIONS CHILDREN'S FUND (UNICEF). 2005. Annual report. New York. UNICEF.

UNITED NATIONS CHILDREN'S FUND (UNICEF). 2007. Annual report. New York. UNICEF.

UNITED NATIONS CHILDREN'S FUND (UNICEF). 2011. The right of children with disabilities to education: a rights-based approach to inclusive education. Geneva. Switzerland.

UNITED NATIONS PROGRAMME ON HIV/AIDS (UNAIDS). 2003. Progress Report on the Global Response to the HIV/AIDS Epidemic. Geneva. Switzerland.

UNITED NATIONS PROGRAMME ON HIV/AIDS (UNAIDS). 2004. Report on the global AIDS epidemic. Geneva: UNAIDS.

WILKINSON, K. 2011. Modelling the impact of taxes and transfers on child poverty in South Africa. Social Science Computer Review, 29(1):127-144.

WOLL, L. 2000. Reporting to the UN committee on the rights of the child: a catalyst for domestic debate and policy change? International Journal of Children's Rights, 8(1):71-81.

Dr Mulugeta Dinbabo, Institute for Social Development, University of the Western Cape, Bellville, South Africa. 